\title{
ICESat measurement of Greenland ice sheet surface slope and roughness
}

\author{
Donghui $\mathrm{YI}^{1}{ }^{1} \mathrm{H}$. Jay ZWALLY, ${ }^{2}$ Xiaoli SUN ${ }^{3}$ \\ ${ }^{1}$ SGT Inc., NASA Goddard Space Flight Center, Code 614.1, Greenbelt, MD 20771, USA \\ E-mail: donghui@icesat2.gsfc.nasa.gov \\ ${ }^{2}$ NASA Goddard Space Flight Center, Code 614.1, Greenbelt, MD 20771, USA \\ ${ }^{3}$ NASA Goddard Space Flight Center, Code 694, Greenbelt, MD 20771, USA
}

\begin{abstract}
The Ice, Cloud and land Elevation Satellite (ICESat) in its 8 day repeat orbit mode provided data not only on the along-track surface slope, but also on the cross-track surface slope from adjacent repeat ground tracks. During the first $\mathbf{3 6}$ days of operation, four to five such repeat orbits occurred within $\mathbf{1 ~ k m}$ in the cross-track direction. This provided an opportunity to use ICESat data to measure surface slope in the cross-track direction at $\mathbf{1} \mathrm{km}$ scale. An algorithm was developed to calculate the cross-track surface slope. Combining the slopes in the cross-track and along-track directions gives a three-dimensional surface slope at $\mathbf{1} \mathrm{km}$ scale. The along-track surface slope and surface roughness at $10 \mathrm{~km}$ scale are also calculated. A comparison between ICESat surface elevation and a European Remote-sensing Satellite (ERS-1) $5 \mathrm{~km}$ digital elevation model shows a difference of 1-2 $\mathrm{m}$ in central Greenland where the surface slope is small, and $>20 \mathrm{~m}$ at the edge of Greenland where the surface slope is large. The large elevation difference at the edge is most likely due to the slope-induced error in radar altimeter measurement. Accurate surface slope data from ICESat will help to correct the slope-induced error of radar altimeter missions such as Geosat, ERS-1 and ERS-2.
\end{abstract}

\section{INTRODUCTION}

The primary purpose of the Ice, Cloud and land Elevation Satellite (ICESat) mission is to detect ice elevation changes that are indicative of changes in ice volume over time in the Greenland and Antarctic ice sheets (Zwally and others, 2002). Other scientific objectives include: measurements of sea-ice, ocean and land-surface elevations and surface roughness; multiple near-surface canopy heights over land; and cloud and aerosol studies. The main instrument on ICESat is the Geoscience Laser Altimeter System (GLAS). GLAS determines the range to the surface by measuring the time between the transmission of the laser pulse and the detection of the echo waveform from the surface. The two GLAS laser wavelengths are $1064 \mathrm{~nm}$ for measuring surface elevation and dense clouds heights, and $532 \mathrm{~nm}$ for measuring backscatter profiles of clouds and aerosols. The full width at half-maximum of the transmitted pulse is $6 \mathrm{~ns}$. The ICESat orbit has an altitude of $600 \mathrm{~km}$ and an inclination of $94^{\circ}$. The laser pulse rate is 40 shots per second.

Ice-sheet surface slope and roughness are mainly affected by bedrock topography, ice flow, ice thickness, wind and mass balance. Accurate surface slope and roughness information can be used to improve the accuracy of both laser altimeter and radar altimeter elevation measurements (Brenner and others, 1983; Zwally and others, 1983; Bamber and others, 1998; Zwally and Brenner, 2001). Bentley and Sheehan (1992) used Geosat Exact Repeat Mission repeat ground-track data to calculate surface slope and then compared the elevations between Seasat and Geosat. Mean surface slope calculated at $1 \mathrm{~km}$ scale will be very useful for similar mass-balance studies. Brenner and others (1990) developed an algorithm to correct geoid-induced variations in repeat orbits over oceans. In this study, data from ICESat 8 day repeat tracks were used to determine the threedimensional surface slope and surface roughness. The ICESat $1064 \mathrm{~nm}$ laser footprint diameter is about $70 \mathrm{~m}$, and footprint separation is $172 \mathrm{~m}$. Surface slope and surface roughness with wavelength $<70 \mathrm{~m}$ can be studied by analysis of the spread of individual laser echo waveforms (Yi and Bentley, 1999). Surface slope and surface roughness with wavelength $>172 \mathrm{~m}$ can be derived from ICESat repeat track elevation profiles.

In this paper, three-dimensional surface slope at $1 \mathrm{~km}$ scale and along-track surface slope and roughness at $10 \mathrm{~km}$ scale are studied. Knowledge of the $1 \mathrm{~km}$ scale surface slope is essential for using satellite altimetry repeat ground tracks to do mass-balance studies. The along-track surface slope and roughness at the $10 \mathrm{~km}$ scale will help to better understand and improve surface elevations from radar altimetry.

ICESat/GLAS has three lasers. The first laser operated from 20 February to 29 March 2003. During this period, ICESat was in its 8 day repeat orbit, which has 119 equally spaced ground tracks to cover the Earth. ICESat also has a 91 day repeat orbit with coverage about 11 times denser than the 8 day orbit. The 91 day orbit is used in later operations.

\section{ALGORITHM}

Satellite laser altimetry involves three basic measurements: (1) the range between the satellite and the laser footprint on the surface; (2) the shape of the echo pulse, which is related to the distribution of surface heights within the footprint; and (3) the echo pulse energy, which is linearly related to surface reflectivity.

ICESat 8 day repeat-orbit ground tracks repeat every 8 days and the repeat ground tracks are within $1 \mathrm{~km}$ of each other in the cross-track direction; the offset occurs because accurate cross-track pointing was not applied in this period. During the first 36 days of operation, four to five repeat orbits occurred within $1 \mathrm{~km}$ in the cross-track direction. This provided an opportunity for ICESat to measure surface slope 


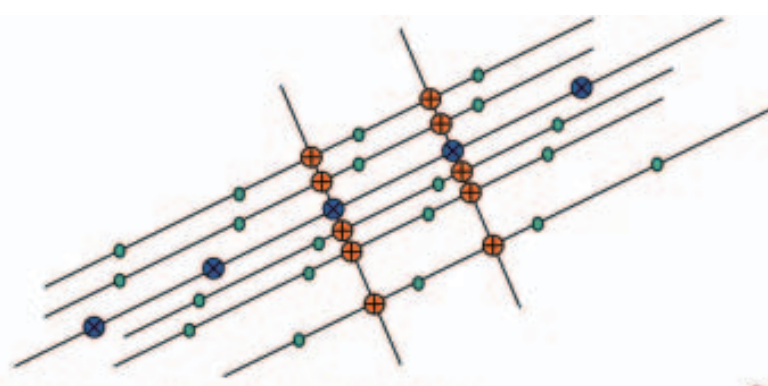

Reference ground track footprint location: Observed ground track footprint location: Aligned footprint location at observed ground track:

Fig. 1. Reference ground track, observed ground track and aligned footprints.

in the cross-track direction at $1 \mathrm{~km}$ scale. In the later ICESat operating periods, accurate pointing was applied and the separation of repeat ground tracks was constrained to within $400 \mathrm{~m}$. Since the ICESat laser sample interval is $172 \mathrm{~m}$ alongtrack, the along-track surface slope on $1 \mathrm{~km}$ scale can be derived from ICESat elevation profiles. An algorithm that uses data from repeat ground tracks to derive the threedimensional surface slope is described below.

There are four major steps in the repeat ground-track elevation analysis: (1) select a reference ground track to align all repeat tracks; (2) align observed data in the alongtrack direction to points on the reference ground track; (3) calculate surface slopes in the cross-track and along-track directions; and (4) combine cross-track and along-track surface slopes and calculate surface roughness along the reference track. ICESat has a reference ground track for the 8 day repeat orbit that is surrounded by the 8 day repeat ground tracks. In mass-balance studies, elevations from repeat ground tracks can be projected to the reference ground track and compared with each other.

Figure 1 shows how to align observed data in the alongtrack direction to points on the reference ground track:

1. select a point on a reference ground track (blue circles);

2. draw a line perpendicular to the reference ground track at this point;

3. find the intersection between this line and an observation track;

4. find the two observed data points adjacent to the intersection (green circles);

5. calculate the elevation on the observed track at this intersection by linearly interpolating from the two adjacent elevations (red circles).

The cross-track slope $\left(S_{\mathrm{c}}\right)$ is derived by fitting a straight line to the along-track-aligned elevations of available repeat cycles as a function of distance to the reference track. The along-track slope $\left(S_{\mathrm{a}}\right)$ is calculated by fitting a line to seven consecutive measured elevations. The three-dimensional slope can be calculated by combining the slopes in the two perpendicular directions. The amplitude of the threedimensional surface slope $S$ can be derived by $\tan ^{2} S=$ $\tan ^{2} S_{\mathrm{a}}+\tan ^{2} S_{\mathrm{c}}$.

The surface slope at a point discussed in this paper is the mean surface slope at that point. For example, $1 \mathrm{~km}$
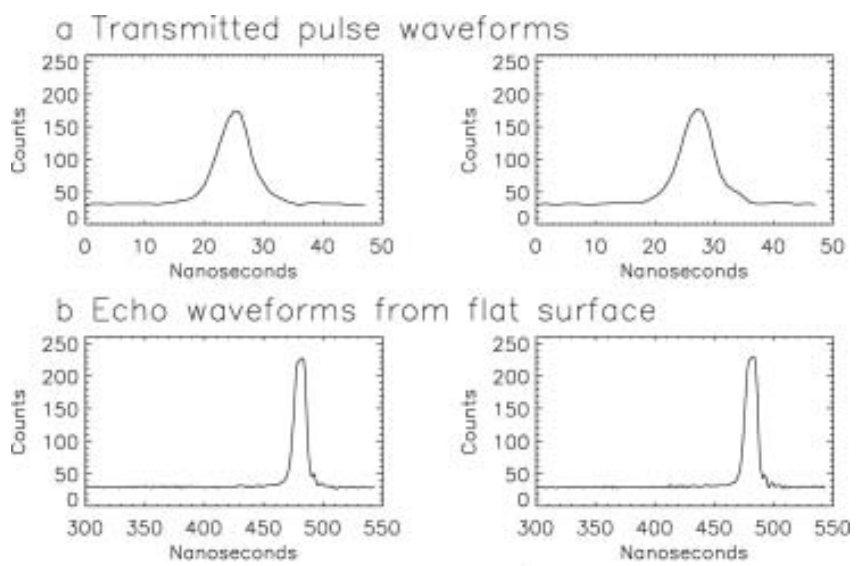

c Echo woveforms from sloping surface
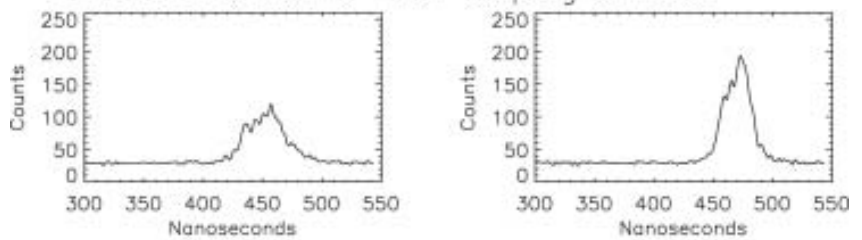

d Forward scattering waveforms
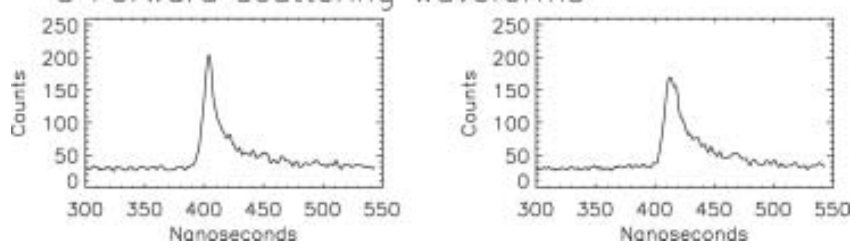

Fig. 2. ICESat sample waveforms.

along-track surface slope at a point is the mean surface slope calculated using data within $500 \mathrm{~m}$ of that point. It is assumed that the surface slope is constant on a $1 \mathrm{~km}$ scale, so linear interpolation can be applied to two points separated by $172 \mathrm{~m}$ (2.5 times the laser footprint size) to align elevations to reference ground tracks. This assumption also makes it possible to calculate cross-track slopes at the $1 \mathrm{~km}$ scale. This is very important for future mass-balance studies, since it will enable the elevation comparison of repeat tracks.

Surface roughness at a point is defined as the standard deviation of the differences between surface elevations and a fitted straight line of the elevations over a distance surrounding the point. Based on this definition, surface roughness will be sensitive to the distance interval selected to do the calculation. Over large distance, such as the $10 \mathrm{~km}$ scale used in this study, surface topography will affect the surface roughness value.

\section{DATA AND RESULTS}

The detected pulse corresponding to the reflections from the surface is digitized in $1 \mathrm{~ns}(15 \mathrm{~cm})$ range bins. The echo waveforms have 544 range bins over ice sheets and land, and 200 range bins over ocean and sea-ice regions. The wider waveform window was chosen for ice sheets and land because they have more surface relief due to their complex surface features such as large surface slope and tall trees. The quality of the waveform is important in determining surface elevation. The ICESat transmitted waveforms (Fig. 2a) are very stable and introduce little error in elevation calculations. The echo waveforms are affected 


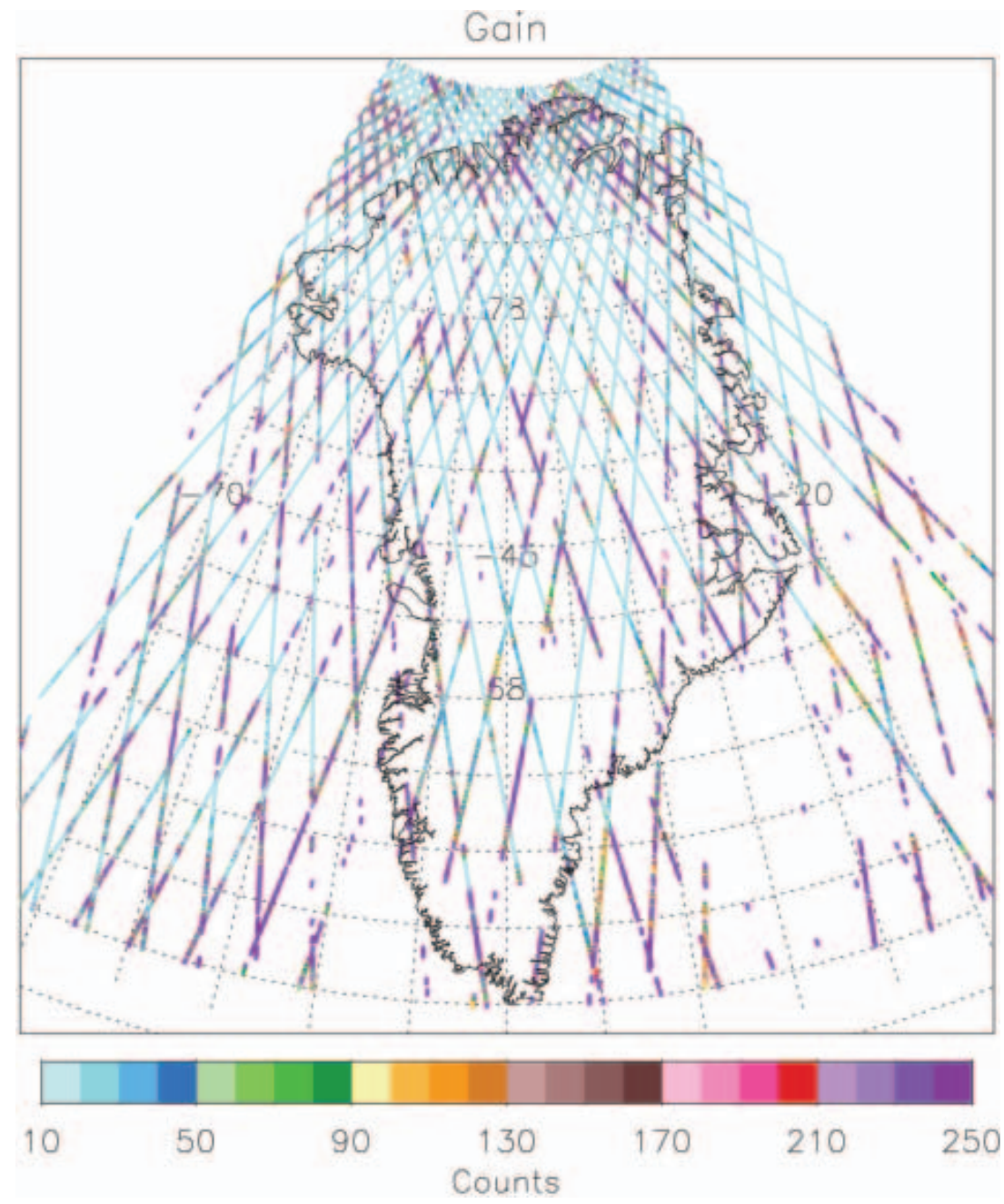

Fig. 3. Detector gain of ICESat 8 day repeat-orbit cycle 4 data.

by the transmitted pulse energy, atmospheric (including cloud) attenuation, surface reflectivity and surface slope and roughness within the laser footprint, all of which affect the accuracy of surface elevation measurement. Figure $2 b$ shows waveforms over central Greenland, which is very flat. Since the transmitted energy is strong, the echo waveforms are slightly saturated. The range error for this kind of saturation can be corrected by post-processing which is discussed later. Figure 2c shows waveforms from the edge of Greenland where the slopes are large. The pulse is broadened by topography and is not saturated. Figure $2 \mathrm{~d}$ shows the effect of forward scattering on waveforms. Clouds attenuated the signal and also scattered laser photons, causing additional path delays and introducing a bias (Brenner and others, 2003). The scattered laser pulse is seen in the trailing edge of the waveforms. This type of waveform, if not corrected, can produce an error larger than $1 \mathrm{~m}$ (Mahesh and others, 2002).

In this study, a limit is applied to the detector gain to filter out heavily saturated waveforms and heavily atmospherically attenuated waveforms. The detector gain for a laser shot is automatically adjusted according to the pulse amplitudes of the previous laser shots. The gain is lower when the echo waveform amplitude becomes higher. Figure 3 shows the detector gain over Greenland for an 8 day cycle. The detector gain is normally below 20 for this operating period under clear-sky conditions, and gain higher than 50 normally means clouded sky. Data with gain above 30 are not used because they are most often associated with clouds. During this period, there are also data that are saturated with high gain due to the limited response time of the gain control loop; this problem is largely eliminated in later operations by an improved onboard gain control algorithm.

Saturation correction has been applied to low-gain saturations. Sun and others (2003) show that the time of flight bias is approximately linearly related to echo pulse energy after it surpasses a certain level. The method in this paper is the same as in Sun and others (2003), but with the coefficients updated after more data have been analyzed. The elevation difference due to saturation $(\Delta H)$ is calculated by

$$
\Delta H=a_{1}\left(E_{R}-a_{2}\right) c / 2,
$$

where $a_{1}=0.22 \mathrm{nsfj}^{-1}, a_{2}=12 \mathrm{fJ}$ is a limit over which the echo waveform is saturated, $E_{R}$ is the echo pulse energy and $C$ is the speed of light. Using this equation, if the echo pulse energy is $20 \mathrm{fJ}$, an elevation adjustment of $0.26 \mathrm{~m}$ is needed.

As an example, data from 8 day ground track No. 76 are shown in Figure 4. Figure 4a shows the surface elevation of five cycles along the same ground track. The differences in elevation between cycle 1 and other cycles vary from $<1 \mathrm{~m}$ in flat areas to $>10 \mathrm{~m}$ at the edge of Greenland. It is difficult to see the elevation differences on this scale. Figure $4 b$ 

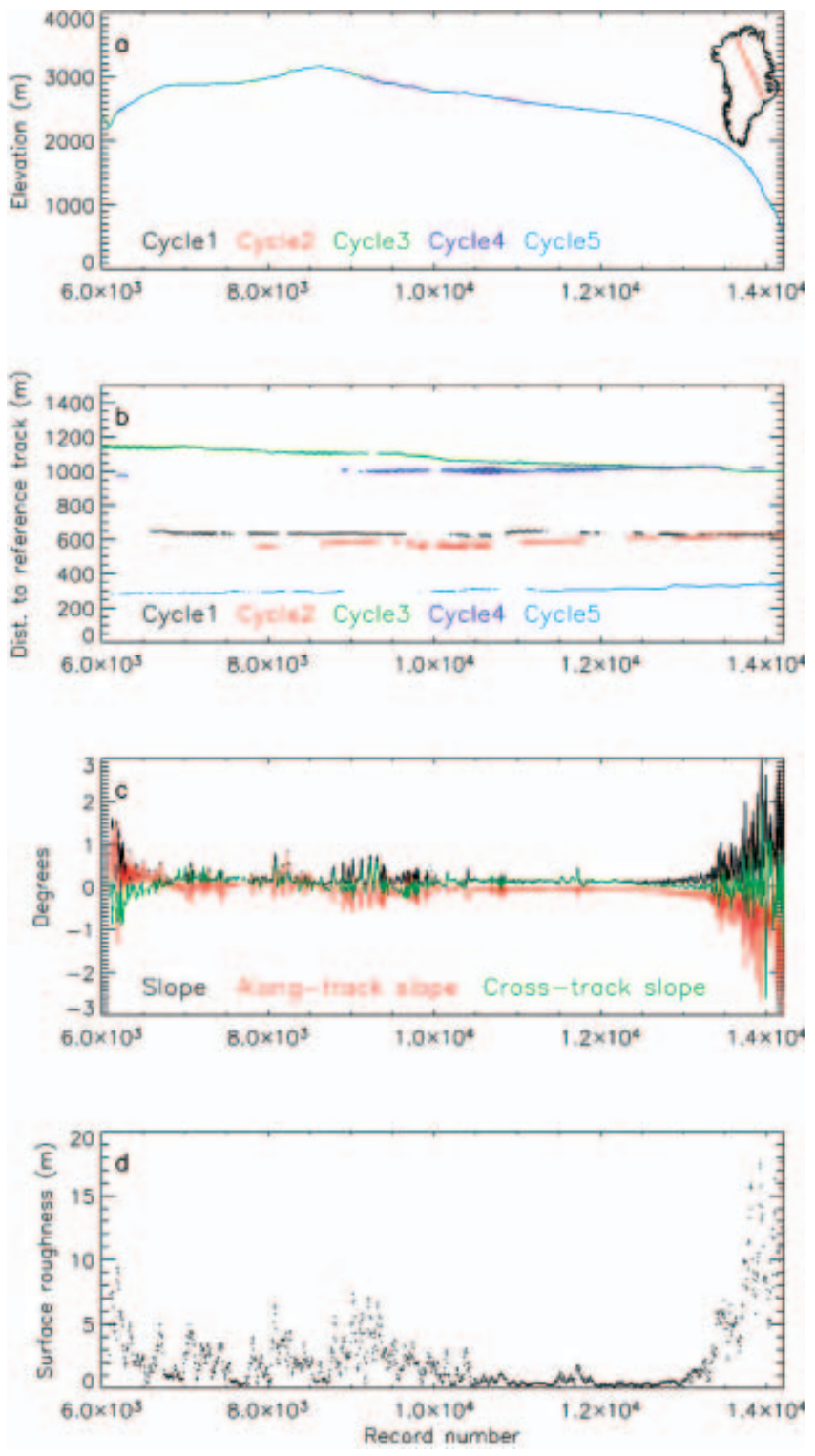

Fig. 4. Eight-day repeat-orbit ground track 76. (a) The elevation profiles (the direction of the profiles is from southeast to northwest on the Greenland map); (b) the distances of five ground track cycles to the reference track; (c) the along-track slope, cross-track slope and the amplitude of the three-dimensional slope; (d) along-track surface roughness.

shows the distances of five ground-track cycles to the reference track. The data gaps and the ground-track variations are clearly shown. Due to jitter and the rotation of ICESat's solar panels, the ground track oscillates along the profile. The sinusoidal cross-track amplitude is not uniform and the vibration has a frequency of about $1 \mathrm{~Hz}$. This ground-track oscillation is not occurring all the time. The data gaps are mostly due to clouds attenuating the signal and thereby preventing the detector from finding an echo. Figure 4c shows the calculated surface slopes in cross-track and along-track directions and their combination. Looking in the ICESat direction of motion, the crosstrack slope is positive if the left side is higher; the alongtrack slope is positive if the elevation is increasing in the direction of movement. At the edge of Greenland, the surface slope reaches $>3^{\circ}$ and is much more variable than in the central part, where it is around $0.1^{\circ}$. Figure $4 d$
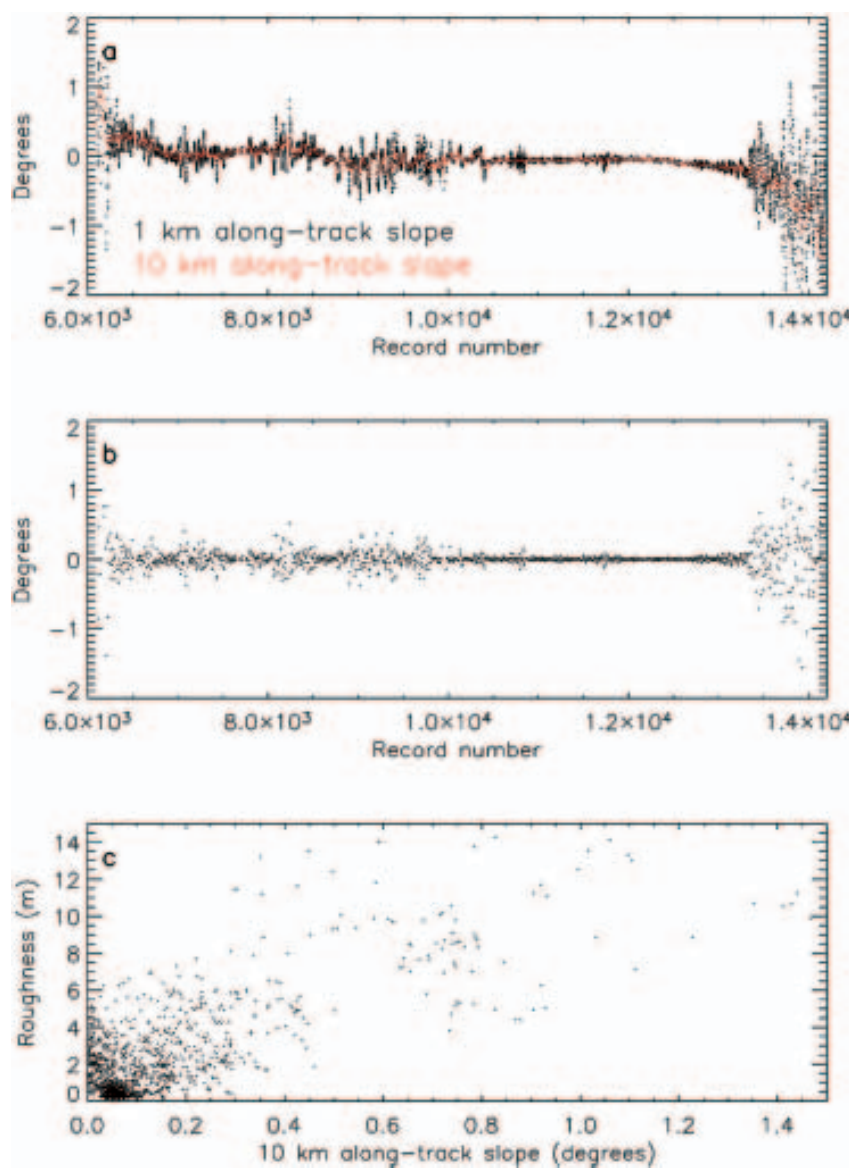

Fig. 5. (a) 1 and $10 \mathrm{~km}$ along-track surface slopes; (b) the difference between 1 and $10 \mathrm{~km}$ along-track surface slopes; (c) surface roughness vs $10 \mathrm{~km}$ along-track surface slope.

shows the surface roughness along the profile. There is a roughness value calculated for every six shots (about $1 \mathrm{~km}$ ). Surface roughness here is defined as the standard deviation of the differences between measured elevation and the fitted line of elevations over a $10 \mathrm{~km}$ span. It varies from $0.1-0.2 \mathrm{~m}$ in the central part of Greenland to $>10 \mathrm{~m}$ at the northern edge.

Track 76 along-track surface slopes, calculated every $1 \mathrm{~km}$ over distances of 1 and $10 \mathrm{~km}$, are compared in Figure $5 \mathrm{a}$. As expected, the $1 \mathrm{~km}$ along-track slope varies more than the $10 \mathrm{~km}$ along-track slope. The difference between the two varies from $<0.1^{\circ}$ in the flat part of the ice sheet to $>1^{\circ}$ at the northern end of the profile (Fig. 5b). Surface roughness and $10 \mathrm{~km}$ along-track slope show no obvious correlation (Fig. 5c). When the $10 \mathrm{~km}$ along-track slope is $>0.5^{\circ}$, surface roughness is $4 \mathrm{~m}$ or higher.

A Greenland $1 \mathrm{~km}$ surface slope map from ICESat 8 day repeat orbit data is shown in Figure 6 . The surface slopes range from $<0.1^{\circ}$ in the central part to $>2.4^{\circ}$ at the edge. Most of the areas that have surface slopes $>0.4^{\circ}$ are within $200 \mathrm{~km}$ of the coast. The data gaps in the map reflect the cloud coverage of Greenland over the period. The southern part, especially near the coast, has more clouds than the rest of Greenland. A Greenland surface roughness map from ICESat 8 day repeat orbit data is shown in Figure 7 . The pattern for Greenland surface roughness distribution is similar to its surface slope distribution. More than $40 \%$ of the calculated roughness values are $<2 \mathrm{~m}$. The roughness 


\section{Surface slope}

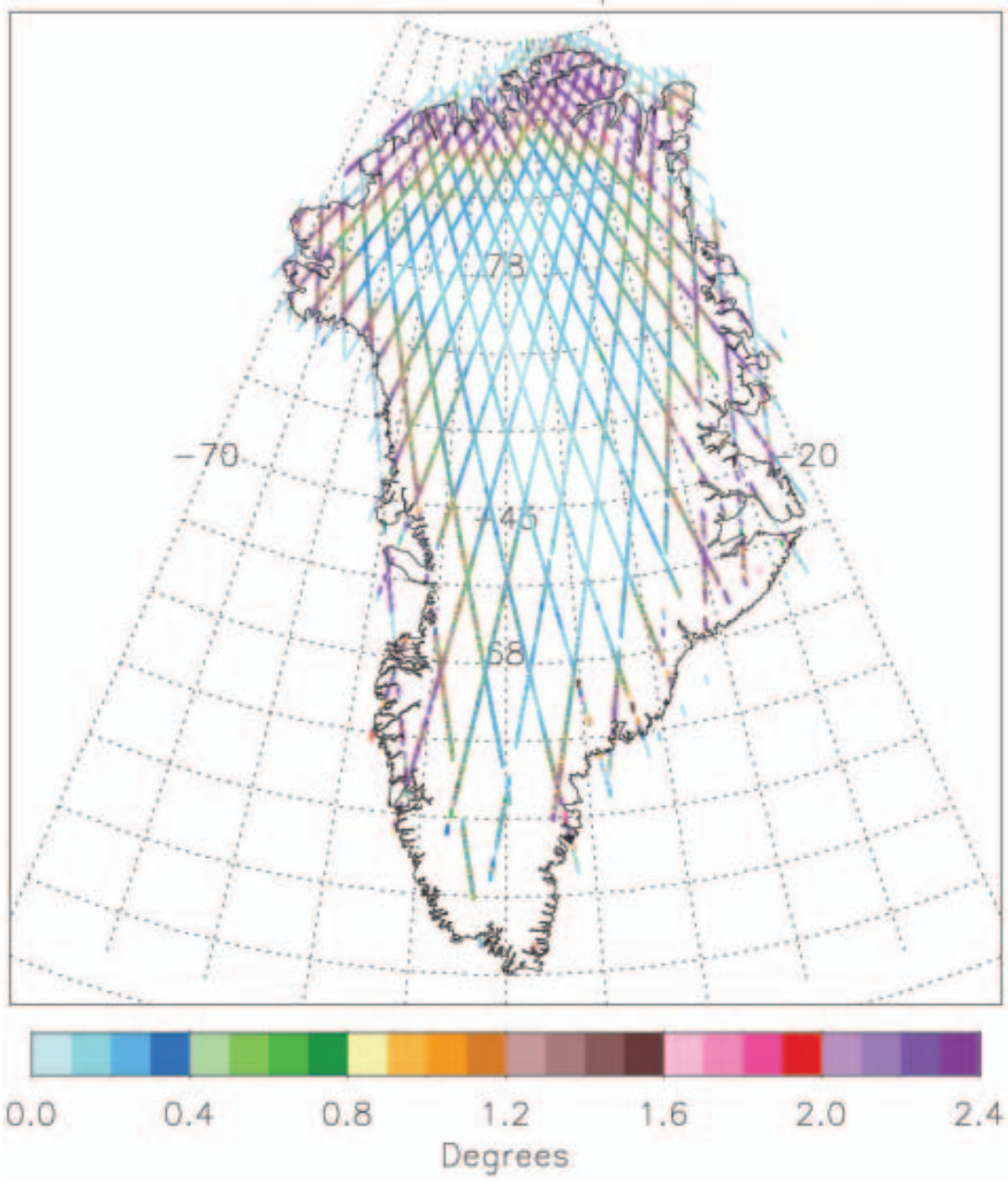

Fig. 6. Greenland $1 \mathrm{~km}$ surface slope amplitude from ICESat 8 day repeat-orbit data.

gradually increases from $0.1 \mathrm{~m}$ at the center to $>12 \mathrm{~m}$ in coastal areas.

The elevation profile of track 76 is compared with the European Remote-sensing Satellite-1 (ERS-1) $5 \mathrm{~km}$ grid digital elevation model (DEM) (DiMarzio and others, 1998) by bilinearly interpolating the elevations of four adjacent gridpoints to an ICESat footprint (Fig. 8). ICESat elevations are $1-2 \mathrm{~m}$ higher than ERS-1 DEM $5 \mathrm{~km}$ grid elevations in central Greenland, and the differences are $>20 \mathrm{~m}$ at the edges. The ERS-1 $5 \mathrm{~km}$ grid DEM data had been compared to the NASA Wallops Flight Facility Aircraft On-board LIDAR (light detection and ranging) (AOL), and the differences are sub-meter in flat areas (DiMarzio and others, 1998). The 1$2 \mathrm{~m}$ differences shown here in central Greenland are likely from factors such as radar altimeter signal penetration of the snow surface and laser-pointing angle uncertainties in ICESat Release 14 data. Real surface elevation changes and the seasonal cycle may also contribute to the differences: ICESat data used here are from March, which is the elevation maximum of the annual cycle (Yi and others, 1997; Zwally and Li, 2002), and the DEM elevation was averaged over an 18 month period. Future ICESat data releases with improved accuracy will give more accurate comparisons. Large differences in Figure 8 over high-slope areas suggest radar altimeters may not have sufficiently accurate surface slope measurements for slope correction.
DiMarzio and others (1998) obtained similar results while comparing ERS-1 $5 \mathrm{~km}$ DEM with AOL data in large-slope regions. Accurate surface slope data from ICESat will help to correct the slope-induced error for radar altimeter missions such as Geosat, ERS-1 and ERS-2.

\section{DISCUSSION}

ICESat data calibration/validation is an ongoing process. Data used in this study are preliminary and do not represent the best capability of ICESat; they will be improved when new releases of ICESat data become available. The quality of the results of this paper will be improved after the data are improved. For ICESat Release 14, the pointing uncertainty is the largest known error source in the data. The designed accuracy of the ICESat laser-pointing angle is 1 arcsec, which will produce a $5 \mathrm{~cm}$ uncertainty over a surface with a $1^{\circ}$ surface slope. Currently, the pointing accuracy is 10 arcsec for the studied period, which gives a $50 \mathrm{~cm}$ uncertainty over a surface with a $1^{\circ}$ surface slope.

For a fixed surface slope between two points, the accuracy depends on the accuracy of the elevation measurements. It also depends on the distance between the two points. For a fixed error in surface elevation, the error in surface slope decreases when the distance increases, assuming a flat surface (see Fig. 9). The predicted 


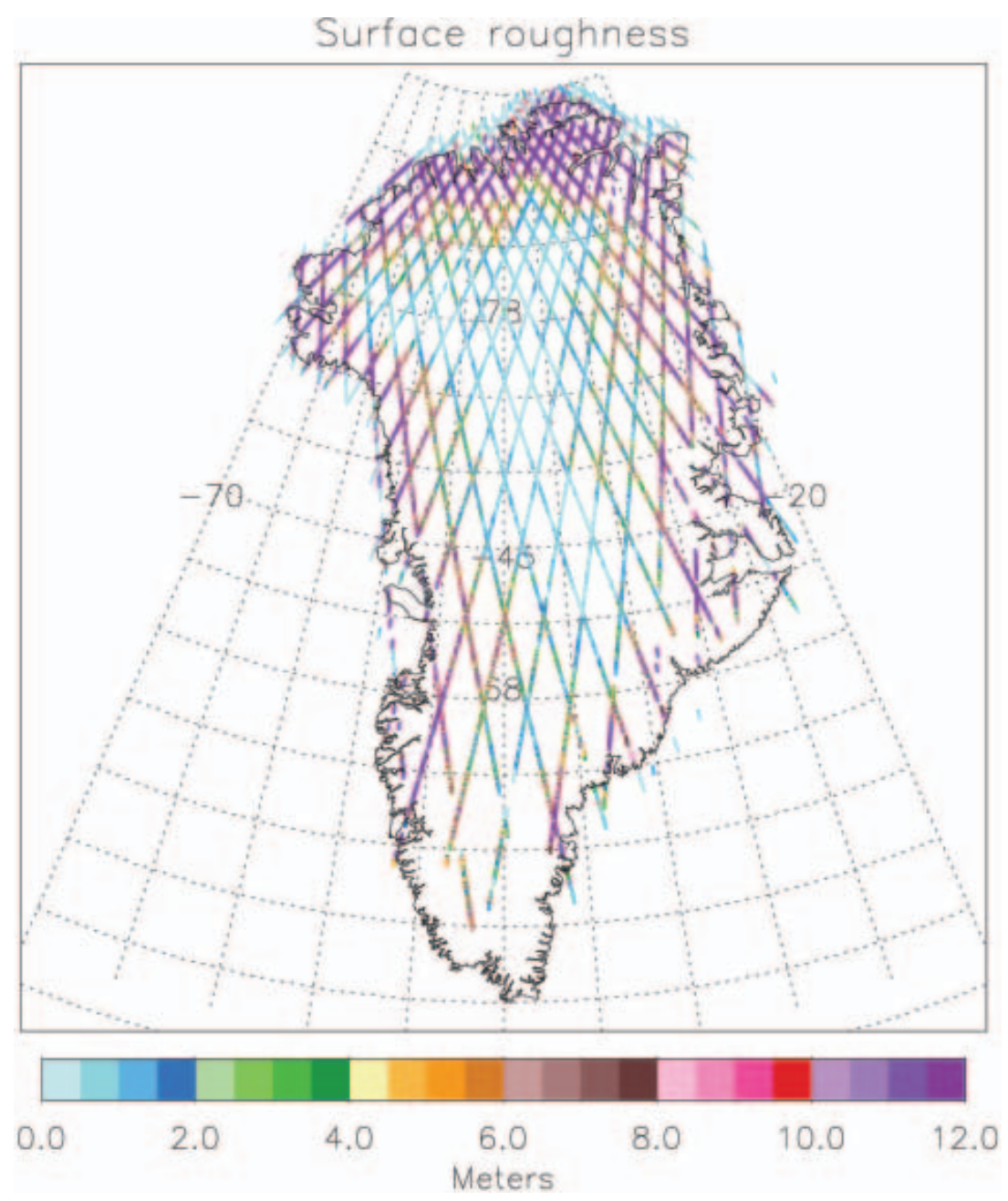

Fig. 7. Greenland surface roughness from ICESat 8 day repeat-orbit data.

accuracy for ICESat elevation is $0.15 \mathrm{~m}$ (Zwally and others, 2002); the corresponding slope errors will be $0.172^{\circ}$, $0.086^{\circ}, 0.017^{\circ}$ and $0.001^{\circ}$ for cross-track separation of 50 , 100,500 and $1000 \mathrm{~m}$ respectively. In this study, surface elevation change during the 38 day period over Greenland is not considered and the slope error is assumed to be from

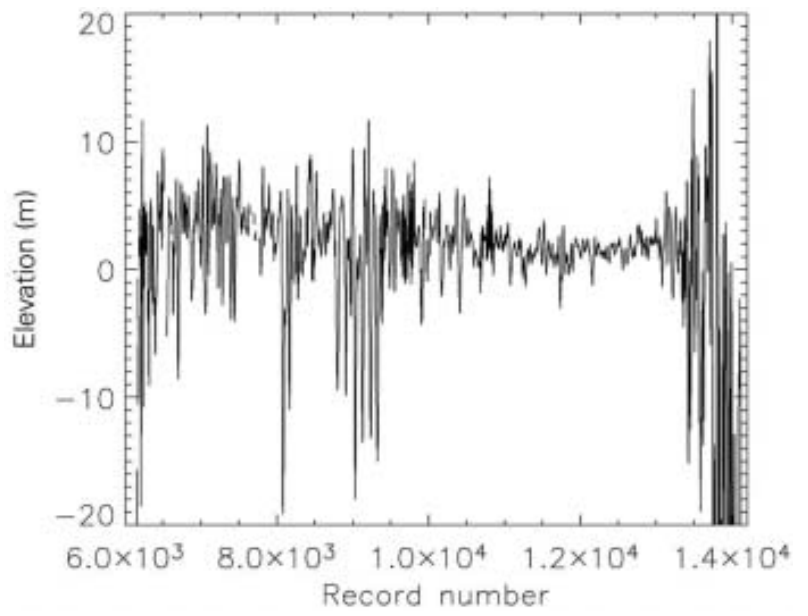

Fig. 8. The difference between ICESat elevation and ERS-1 $5 \mathrm{~km}$ grid DEM. Positive number means ICESat elevation is higher.
ICESat measurement. The elevation change over time would also introduce an error in slope calculation since surface elevations for different repeat cycles are measured at different times.

All results shown here are calculated from ICESat Release 14 data. New data releases will improve elevation values by

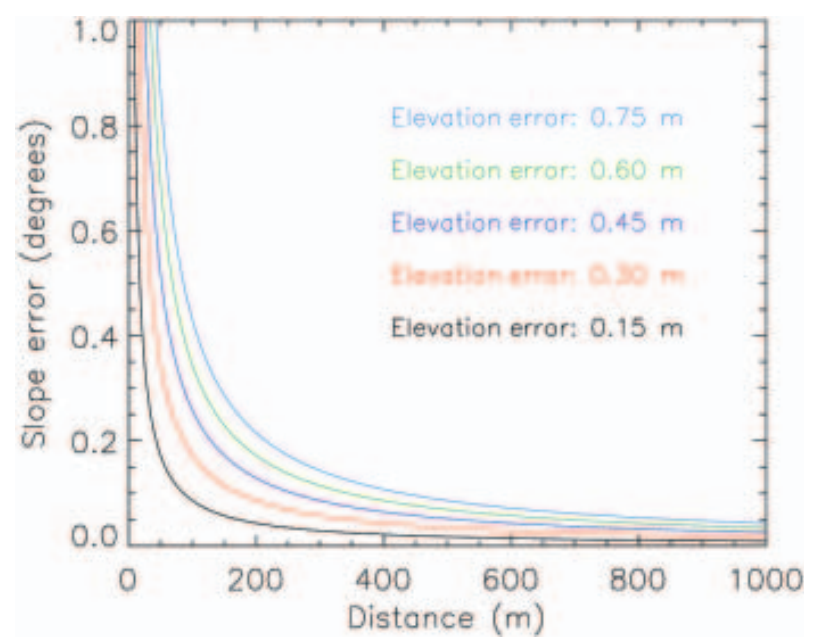

Fig. 9. Surface slope error as a function of elevation error and ground-track separation. For any given distance, slope error increases with elevation error. 
using more accurate laser-pointing information, which will also affect the distance between ground tracks used in this study. This research demonstrates ICESat's ability to measure surface slope in the cross-track direction using slightly separated repeat ground tracks. Improved pointing for later ICESat operations will reduce the repeat ground-track distance (to most likely within $400 \mathrm{~m}$ ) and increase the slope error in the cross-track direction. The improved pointing will also improve the elevation measurement accuracy, which will improve the slope measurement.

The difference between along-track and cross-track slope (Fig. 4c) indicates that the along-track slope alone is inadequate to represent surface slope. Three-dimensional surface slope from the ICESat 8 day repeat orbit data may be used in slope correction to improve radar altimeter measured surface elevation. The difference between 1 and $10 \mathrm{~km}$ along-track slopes (Fig. 5b) indicates that the smaller-scale surface slope interpolated from DEM grids may introduce significant error except over very flat regions such as central Greenland. Once the saturation correction algorithm for echo pulse width is developed, the small-scale $(<70 \mathrm{~m})$ surface slope and surface roughness will be derived from individual echo waveforms.

The study of surface slope at repeat ground-track separation scale is the base of using repeat ground tracks to study ice-sheet mass balance. Knowing cross-track slope will make it possible to compare elevations and calculate elevation changes along repeat ground tracks. This will use all data points while the traditional crossover method (Zwally and others, 1989) only uses data adjacent to crossover points.

\section{ACKNOWLEDGEMENTS}

This work is supported by NASA's funding of the ICESat/ GLAS Science Team. We thank the reviewers M. Nolan and F. Cawkwell for their helpful comments on the manuscript.

\section{REFERENCES}

Bamber, J.L., S. Ekholm and W.B. Krabill. 1998. The accuracy of satellite radar altimeter data over the Greenland ice sheet determined from airborne laser data. Geophys. Res. Lett., 25(16), 3177-3180.
Bentley, C.R. and D.D. Sheehan. 1992. Comparison of altimetry profiles over East Antarctica from Seasat and Geosat: an interim report. Z. Gletscherkd. Glazialgeol., 26(1), 1-9.

Brenner, A.C., R.A. Bindschadler, R.H. Thomas and H.J. Zwally. 1983. Slope-induced errors in radar altimetry over continental ice sheets. J. Geophys. Res., 88(C3), 1617-1623.

Brenner, A.C., C.J. Koblinsky and B.D. Beckley. 1990. A preliminary estimate of geoid-induced variations in repeat orbit satellite altimeter observations. J. Geophys. Res., 95(C3), 3033-3040.

Brenner, A.C. and 10 others. 2003. Derivation of range and range distributions from laser pulse waveform analysis for surface elevations, roughness, slope and vegetation heights. Algorithm Theoretical Basis Document, Version 4.1. Greenbelt, MD, NASA Goddard Space Flight Center.

DiMarzio, J.P., A.C. Brenner, J.L. Saba and H.J. Zwally. 1998. Improved Antarctic and Greenland topography from ERS-1 and Geosat geodetic mission altimetry. [Abstract H22A-2.] EOS Trans. AGU, 79(17), Spring Meet. Suppl., S80.

Mahesh, A., J.D. Spinhirne, D.P. Duda and E.W. Eloranta. 2002. Atmospheric multiple scattering effects on GLAS altimetry Part II: analysis of expected errors in Antarctic altitude measurements. IEEE T. Geosci. Remote, 40(11), 2353.

Sun, X., J.B. Abshire and D. Yi. 2003. Geoscience laser altimeter system (GLAS): characteristics and performance of the altimeter receiver. [Abstract C32A-0432.] EOS Trans. AGU, 84(46), Fall Meet. Suppl., F383.

Yi, D. and C.R. Bentley. 1999. Geoscience Laser Altimeter System waveform simulation and its applications. Ann. Glaciol., 29, 279-285.

Yi, D., C.R. Bentley and M.D. Stenoien. 1997. Seasonal variation in the apparent height of the East Antarctic ice sheet. Ann. Glaciol., 24, 191-198.

Zwally, H.J. and A.C. Brenner. 2001. Ice sheet dynamics and mass balance. In Fu, L.-L. and A. Cazanave, eds. Satellite altimetry and earth sciences. New York, Academic Press Inc., 351-369. (International Geophysical Series 69.)

Zwally, H.J. and J. Li. 2002. Seasonal and interannual variations of firn densification and ice-sheet surface elevation at Greenland summit. J. Glaciol., 48(161), 199-207.

Zwally, H.J., R.A. Bindschadler, A.C. Brenner, T.V. Martin and R.H. Thomas. 1983. Surface elevation contours of Greenland and Antarctic ice sheets. J. Geophys. Res., 88(C3), 1589-1596.

Zwally, H.J., A.C. Brenner, J.A. Major, R.A. Bindschadler and J.G. Marsh. 1989. Growth of Greenland ice sheet: measurement. Science, 246(4937), 1587-1589.

Zwally, H.J. and 15 others. 2002. ICESat's laser measurements of polar ice, atmosphere, ocean and land. J. Geodyn., 34(3-4), 405-445. 